\title{
CORRIGENDA
}

\section{Increasing incidence and geographic distribution of neonatal abstinence syndrome: United States 2009 to 2012}

SW Patrick, MM Davis, CU Lehman and WO Cooper

Journal of Perinatology (2015) 35, 667. doi:10.1038/jp.2015.63

Correction to: Journal of Perinatology; advance online publication, 30 April 2015; doi:10.1038/jp.2015.36
Following publication of this article, the authors noticed that the third author's name was missing a letter. The correct spelling of the author's name should be CU Lehmann.

\section{Parathyroid hormone as a marker for metabolic bone disease of prematurity}

A Moreira, L Swischuk, M Malloy, D Mudd, C Blanco and C Geary

Journal of Perinatology (2015) 35, 667. doi:10.1038/jp.2015.64

Correction to: Journal of Perinatology (2014) 34, 787-791;

Throughout the text, the units for concentrations of parathyroid doi:10.1038/jp.2014.97; published online 29 May 2014 hormone were incorrectly presented as $\mathrm{mg} \mathrm{dl}^{-1}$. The correct unit is $\mathrm{pg} \mathrm{ml}^{-1}$. The authors regret the error. 